\title{
Dual targeting of CCR2 and CX3CR1 in an arterial injury model of vascular inflammation
}

\author{
Maya R Jerath ${ }^{1}$, Peng Liu', Mary Struthers², Julie A DeMartino², Roche Peng², Laurence B Peterson², \\ Anne-Marie Cumiskey ${ }^{2}$, Lihu Yang ${ }^{2}$, Mauricio Rojas ${ }^{1}$, Dhavalkumar D Patel ${ }^{1,3}$, Alan M Fong ${ }^{1 *}$
}

\begin{abstract}
Objectives: The chemokine receptors CCR2 and CX3CR1 are important in the development of coronary artery disease. The purpose of this study is to analyze the effect of a novel CCR2 inhibitor in conjunction with CX3CR1 deletion on vascular inflammation.

Methods: The novel CCR2 antagonist MRL-677 was characterized using an in vivo model of monocyte migration. To determine the relative roles of CCR2 and CX3CR1 in vascular remodeling, normal or CX3CR1 deficient mice were treated with MRL-677. After 14 days, the level of intimal hyperplasia in the artery was visualized by paraffin sectioning and histology of the hind limbs.

Results: MRL-677 is a CCR2 antagonist that is effective in blocking macrophage trafficking in a peritoneal thioglycollate model. Intimal hyperplasia resulting from vascular injury was also assessed in mice. Based on the whole-blood potency of MRL-677, sufficient drug levels were maintained for the entire 14 day experimental period to afford good coverage of mCCR2 with MRL-677. Blocking CCR2 with MRL-677 resulted in a 56\% decrease in the vascular injury response $(n=9, p<0.05)$ in normal animals. Mice in which both CCR2 and CX3CR1 pathways were targeted (CX3CR1 KO mice given MRL-677) had an 88\% decrease in the injury response ( $n=6, p=0.009$ ).

Conclusion: In this study we have shown that blocking CCR2 with a low molecular weight antagonist ameliorates the inflammatory response to vascular injury. The protective effect of CCR2 blockade is increased in the presence of CX3CR1 deficiency suggesting that CX3CR1 and CCR2 have non-redundant functions in the progression of vascular inflammation.
\end{abstract}

\section{Background}

Atherosclerosis is an inflammatory process that is initiated by endothelial dysfunction leading to an increase in adhesiveness of platelets and lymphocytes to the injured region of the artery[1]. The inflammatory response continues with the migration of monocyte derived macrophages, dendritic cells, and a subset of $\mathrm{T}$ cells to the area. Finally, smooth muscle cell migration and proliferation occurs. Chemokines and their receptors play an important regulatory role for these processes and genetic studies have revealed specific polymorphisms that are associated with coronary artery disease and carotid artery occlusive disease in man[2,3]. Two chemokine receptors, CX3CR1 and CCR2, have

\footnotetext{
* Correspondence: afong@med.unc.edu

'Department of Medicine, University of North Carolina, Chapel Hill, NC, USA
} Full list of author information is available at the end of the article been widely studied in mouse models of inflammatory disease. Each receptor has been shown to play a role in inflammatory cell trafficking. CX3CR1 is expressed on monocytes, natural killer cells, and a subset of $\mathrm{T}$ cells [4]. CX3CR1 is also found on smooth muscle cells[5]. Its ligand CX3CL1 (fractalkine) is a membrane bound chemokine that is increased in atherosclerosis[6]. We have shown that this molecular pair can mediate leukocyte adhesion and migration under physiological flow conditions in vitro[7]. In addition, using CX3CR1 deficient animals, we have shown that these mice have decreased macrophage and dendritic cell accumulation during vascular inflammation and are protected from intimal hyperplasia in an arterial injury model $[8,9]$. Similarly CCR2 is also expressed on the majority of blood monocytes, a subset of $\mathrm{T}$ cells, as well as other leukocytes. CCR2 is responsible for directed cell migration towards its primary ligand monocyte chemotactic
C Biomed Central

C 2010 Jerath et al; licensee BioMed Central Ltd. This is an Open Access article distributed under the terms of the Creative Commons Attribution License (http://creativecommons.org/licenses/by/2.0), which permits unrestricted use, distribution, and reproduction in any medium, provided the original work is properly cited. 
protein 1 (MCP-1, CCL2) and can also respond to other chemokines of the MCP family [10]. Furthermore, CCR2 deficient animals exhibit a decreased susceptibility to atherosclerosis and also decreased intimal hyperplasia following arterial injury[11,12]. These two receptors are differentially expressed in monocyte subsets across species from rodent to man[13]. Recent results show that monocyte migration following kidney ischemia reperfusion injury is dependent on both CCR2 and CX3CR1 [14]. We hypothesized that CCR2 and CX3CR1 have non-redundant effects in vascular inflammation and sought to determine their combined effect in a murine arterial injury model. Arterial injury induces vessel wall inflammation by stimulating platelet adherence, leukocyte recruitment, and vascular smooth muscle cell migration and proliferation. These same cellular responses are the basis of atherosclerosis and restenosis.

\section{Methods}

\section{Monocyte recruitment}

Defined pathogen-free female C57Bl/6 mice were purchased from Taconic Farms and housed in a sterile pathogen-free environment. Monocytes were recruited to the peritoneal cavity over the course of 3 days following a single i.p. injection of $1 \mathrm{ml}$ sterile $10 \%$ Brewer's thioglycollate medium. Three days after the injection of thioglycollate, peritoneal exudate cells (PECs) were lavaged from the mice with two $5 \mathrm{ml}$ washes of warm Dulbecco's PBS (without $\mathrm{Ca}^{++}$and $\mathrm{Mg}^{++}$) containing 5\% fetal calf serum and 10 units $/ \mathrm{ml}$ heparin. All groups contained 10 mice. Following lavage, PECs from each mouse were washed once with Dulbeccos PBS containing $5 \%$ fetal calf serum and the total number of viable cells was determined microscopically with trypan blue. FACS analysis was used to determine the total number of monocytes per mouse by staining with FITC anti F4/ 80. MRL-677 [patent: US7230008 B2 Appl. No. US2004923594A], or an equivalent volume $(0.5 \mathrm{ml})$ of vehicle (DMSO:Cremophor:Saline, 2:4:94, v:v:v) were administered by oral gavage at the indicated doses once a day during the 3 day thioglycollate elicitation.

\section{Affinity of MRL-677 for CCR2 in whole blood}

Germ free C57Bl/6 mice obtained from Taconic were used for the following experiments. Murine blood was collected by cardiac puncture into tubes containing EDTA to inhibit clotting. For each sample, blood from three to four animals was pooled together and diluted 1:1 with cold PBS containing 1 mM EDTA. MRL-677 (100 X concentration) in DMSO (50 $\mu \mathrm{l})$ was added to $5 \mathrm{ml}$ of blood to achieve the desired concentration and these samples incubated for 1 hour at RT with gentle rotation. PBMCs were rapidly isolated on Ficoll-Hypaque gradients (Lympholyte-Mammal Cedarlane laboratories Cat \#
CL5120). The buffy coat containing principally monocytes and lymphocytes (PBMCs) was isolated from the interface layer and transferred to a fresh tube. The medium was aspirated after centrifugation and $5 \mathrm{ml}$ cold RBC lysis buffer (Sigma, Cat \# R7757 155 mM ammonium chloride in $10 \mathrm{mM}$ Tris- $\mathrm{HCl}$ buffer) was added and incubated for $5 \mathrm{~min}$ at RT to lyse residual red blood cells. Cold PBS (without $\mathrm{Ca}^{++} / \mathrm{Mg}^{++}$) was added to $10 \mathrm{ml}$, and cells harvested by centrifuging at $1200 \mathrm{rpm}$, for $6 \mathrm{~min}$ at $4^{\circ} \mathrm{C}$. Cells were resuspended in approximately $0.8 \mathrm{ml}$ cold binding buffer (50 mM HEPES, pH 7.2; $5 \mathrm{mM} \mathrm{MgCl}_{2}$; $\mathrm{mM} \mathrm{CaCl}{ }_{2} ; 0.5 \%$ BSA and protease inhibitor cocktail (Sigma \#P8340). An aliquot of these cells was retained to permit precise cell number determinations. ${ }^{125}$ I-murine MCP-1 (mMCP-1) binding to cells was then determined by standard filtration binding assays. Briefly $120 \mu \mathrm{l}$ of binding buffer with $25 \mathrm{\mu l}^{125} \mathrm{I}$-mouse MCP-1 $\left(4 \times 10^{4}\right.$ $\mathrm{cpm}, 40 \mathrm{pM})$ and $100 \mu \mathrm{l}$ intact cells $(500,000)$ were incubating for 1 hour at RT. The non-specific binding for each sample was determined by the inclusion of excess unlabeled mMCP-1 (200 nM) into an identical reaction mixture for 1 hour at RT.

\section{Murine vascular injury model}

CX3CR1 knockout animals were backcrossed onto the C57Bl/6 background for 12 generations. Normal wildtype animals (Jackson laboratories) were used for controls. The femoral artery injury was performed using a procedure previously described[8]. Briefly, femoral arteries of 8-12 week old male mice in each experimental arm were injured by endoluminal passage of an angioplasty guidewire under general anesthesia. Mice were recovered and monitored after surgery. 14 days after injury, the mice were perfused with $4 \%$ paraformaldehyde for 20 minutes via cannulation of the left ventricle. The hind limbs were then harvested en bloc, fixed in paraformaldehyde and decalcified. Tissues containing the femoral artery were embedded in paraffin and cut into $5 \mathrm{~mm}$ sections for histologic and morphometric analysis.

In animals given MRL-677, the drug was administered by oral gavage at $30 \mathrm{mg} / \mathrm{kg}$ for the first two days of the protocol and thereafter in feed at an approximate dose of $15 \mathrm{mg} / \mathrm{kg} /$ day throughout the 14 days postoperatively. Blood levels of the antagonist were measured at times corresponding to peak (morning) and trough (evening).

\section{Histochemistry}

Six to ten sections per femoral artery at $100 \mu \mathrm{m}$ intervals were stained with hematoxylin and eosin. The sections from the area with maximal injury response were further evaluated by staining with the Combined Masson's elastin (CME) stain to visualize the arterial wall layers. The area of the vessel lumen, intima, and media 
were measured by computerized morphometry (Image J, $\mathrm{NIH}$ ). Intimal hyperplasia was defined as the formation of a neointimal layer within the internal elastic lamina (IEL). Data were analyzed by t-test and $\mathrm{p}<0.05$ was considered significant.

\section{Immunohistochemistry}

The serial sections embedded in paraffin were immunostained to detect the presence of monocytes using procedures previously described[8]. Briefly, after deparrafinization, the slides were treated with $0.3 \%$ hydrogen peroxide to inactivate endogenous peroxidase, washed in TBS, and antigen retrieval performed by incubating in a solution containing $0.1 \% \mathrm{CaCl}_{2}$ and $0.1 \%$ trypsin for 30 minutes at $37 \mathrm{C}$. After washing in TBS and blocking in $10 \%$ normal rabbit serum, the sections were incubated in a 1:250 dilution of F4/80 antibody (Serotec) overnight at $4 \mathrm{C}$. The following day, the samples were washed in TBS and incubated in a rat anti mouse biotinylated secondary antibody (1:100 dilution) for 1 hour. After washing in TBS, the samples were incubated in streptavidenhorseradish peroxidase (Peroxidase Vectastain ABC kit, Vector Labs) for 1 hour at room temperature. The monocytes were then visualized using 3,3'diaminobenzadine (DAB, Sigma, St. Louis, Mo) as a substrate and the sections were counterstained with Gills solution.

\section{Results}

We have previously shown that CX3CR1 knockout mice display a $58 \%$ decrease in intimal hyperplasia in a vascular injury model relative to wildtype animals [8]. In order to determine any relationship between the involvement of CX3CR1 and CCR2 in the inflammatory response in this model, we tested the effect of a specific CCR2 antagonist (MRL-677) in CX3CR1 knockout mice.

MRL-677 has a murine whole blood potency $\left(\mathrm{IC}_{50}\right)$ of $3.2 \mathrm{nM}$ as determined by the ability to block ${ }^{125} \mathrm{I}$ labeled-mCCL2 binding to peripheral blood mononuclear cells (PBMC) after in vitro whole blood treatment (Figure 1A). This is consistent with the potency of the compound to block mCCL2 binding to cells expressing recombinant $\mathrm{mCCR} 2\left(\mathrm{IC}_{50}=1.8 \pm 0.4 \mathrm{nM}\right)$, with a slight shift noted in whole blood, likely due to protein binding. MRL-677 was at least 100-fold more effective in inhibiting CCR2 compared to other chemokine receptors in standard competition binding experiments: murine CCR 5 (selectivity $>200$ fold), human CCR 1 (selectivity $>5000$ fold), CCR3 (selectivity $>500$ fold), CCR8 (selectivity $>500$ fold), CXCR1 (selectivity $>5000$ fold), CXCR2 (selectivity $>5000$ fold), and CXCR3 (selectivity $>500$ fold). Table 1 summarizes the findings. All assays were performed as competition binding assays using radioactively labeled chemokine receptor ligands.

To confirm the activity of MRL-677 in vivo, we evaluated its effect of CCR2 blockade on monocyte recruitment in response to inflammation in $\mathrm{C} 57 \mathrm{Bl} 6$ mice. The intraperitoneal administration of thioglycollate evoked a robust monocyte infiltration to the murine peritoneal cavity $\left(26 \pm 6 \times 10^{6}\right.$ cells $)$ compared to mice without application of thioglycollate $\left(1 \times 10^{6}\right.$ cells $)$. Administration of MRL-677 at doses of 3, 10, or $30 \mathrm{mg} / \mathrm{kg} /$ day inhibited monocyte recruitment in the peritoneal cavity upon thioglycollate stimulation by approximately $49 \%$, $75 \%$, and $89 \%$ respectively (Figure $1 \mathrm{~B}$ ). Drug levels of
A

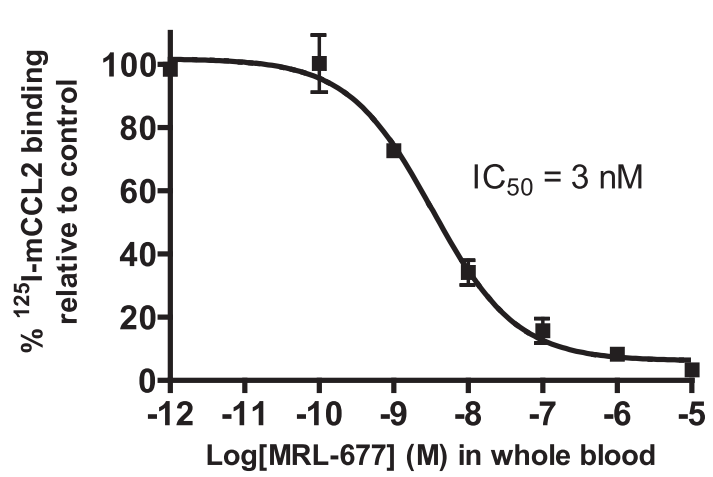

B

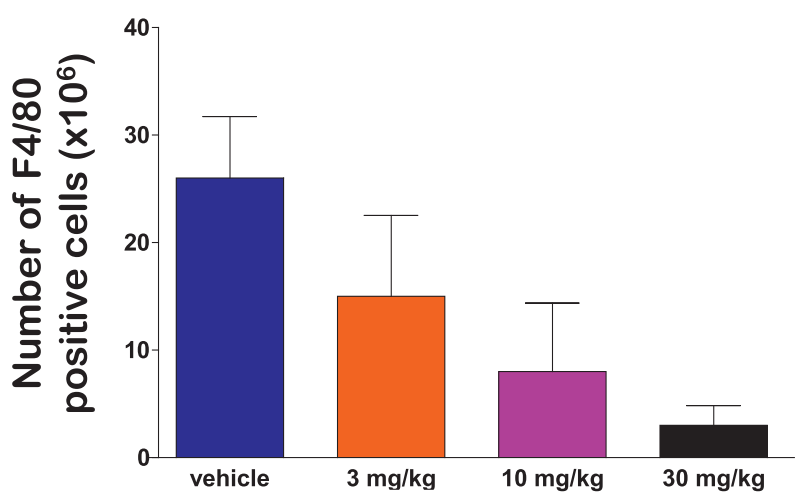

Figure 1 A) MRL-677 added to murine whole blood at the concentrations indicated inhibited the binding of mCCR2 on PBMCs . Each point represents the average of three measurements and the error bars represent the standard error of the mean. The potency $\left(I C_{50}\right)$ of the compound was determined to be $3.2 \mathrm{nM}$ (+ $0.1 \mathrm{SE}$ ) and was determined by a four parameter fit of the data as shown. B) MRL-677 given orally inhibits recruitment of monocytes into the peritoneal cavity. The number of monocytes recruited to the peritoneal cavity was quantitated by F4/ 80 staining of the cellular exudate on day 3 post-intraperitoneal thioglycollate administration. Oral administration of MRL-677 for the three days at the doses indicated was able to inhibit monocyte recruitment to the peritoneal cavity. 
Table 1 CCR2 Antagonist MRL-677 Competition

\begin{tabular}{ll}
\hline & IC $_{\mathbf{5 0}}$ or \% inhibition \\
\hline Murine CCR2 & $1.8 \pm 0.4 \mathrm{nM}$ \\
\hline Murine CCR5 & $418 \pm 76 \mathrm{nM}$ \\
\hline Human CCR1 & $24 \%$ @ $10 \mu \mathrm{M}$ \\
\hline Human CCR3 & No inhibition @ $1 \mu \mathrm{M}$ \\
\hline Human CCR8 & No inhibition @ $1 \mu \mathrm{M}$ \\
\hline Human CXCR1 & $8 \% @ 10 \mu \mathrm{M}$ \\
\hline Human CXCR2 & $11 \%$ @ $1 \mu \mathrm{M}$ \\
\hline Human CXCR3 & $3 \%$ @ $1 \mu \mathrm{M}$ \\
\hline
\end{tabular}

MRL-677 assessed at trough for these experiments were below the limit of detection $(<1 \mathrm{nM}) 24$ hours after 3 and $10 \mathrm{mg} / \mathrm{kg} /$ day doses and was $5 \mathrm{nM} 24$ hours after the highest dose tested at $30 \mathrm{mg} / \mathrm{kg} /$ day. Therefore, MRL-677 was administered by oral gavage at $30 \mathrm{mg} / \mathrm{kg}$ for the first two days and thereafter in feed at a dose of $\sim 15 \mathrm{mg} / \mathrm{kg} /$ day in order to evaluate the effect of inhibiting CCR2 on vascular inflammation in response to injury. In addition to reducing animal handling and the stress that accompanies it, the administration of the drug in feed was anticipated to lead to higher trough drug levels to ensure complete blockade.

In the vascular injury experiments, we first measured the blood concentration of MRL-677 everyday for the complete experimental course of 14 days in both wildtype and CX3CR1 KO mice. We achieved an average trough level of $0.43 \pm 0.11 \mu \mathrm{M}$ for wildtype mice and $0.68 \pm 0.41 \mu \mathrm{M}$ for CX3CR1 KO mice. This indicates that sustained therapeutic drug concentrations considerably greater than those anticipated to give $>95 \%$ coverage of CCR2 based on the mouse whole blood potency (whole blood $\mathrm{IC}_{95}=0.06 \mu \mathrm{M}$, corresponding to 19 fold the $\mathrm{IC}_{50}$ ) were achieved during the 14 day treatment.

Then we examined the intimal hyperplasia by measuring the ratio of the area of the intima over the media (I/ $\mathrm{M}$ ratio) 14 days after the femoral artery injury procedure. Treatment of wildtype mice with the CCR2 antagonist resulted in 56\% reduction in intimal hyperplasia compared to wildtype mice without antagonist treatment $(0.482 \pm 0.097$ vs. $0.213 \pm 0.05, \mathrm{p}<0.05)$ (Figure 2). In addition, the degree of protection from intimal hyperplasia observed in the normal mice fed the drug is similar to that seen in CCR2 deficient mice $(0.213 \pm 0.05$ vs. $0.133 \pm 0.084, \mathrm{p}=\mathrm{NS})$. Furthermore, there was a dramatic reduction in vascular injury observed in the CX3CR1 $\mathrm{KO}$ animals given the CCR2 antagonist $(\mathrm{I} / \mathrm{M}$ ratio of $0.056 \pm 0.017)$ in which there was an $88 \%$ decrease in the development of intimal hyperplasia relative to untreated wildtype animals. Thus, knocking out the CX3CR1 pathway together with blocking CCR2 function via MRL-677 significantly decreased the intimal hyperplasia and this decrease is greater than inhibiting CCR2 alone ( $p=0.009$, Figure 3$)$. In order to determine whether or not monocyte trafficking played a role in the change in intimal hyperplasia observed, we performed immunohistochemistry on sections. Figure 4 shows that while monocytes are seen in injured femoral arteries from wildtype mice, there is a significant decrease in monocyte numbers in MRL-677 treated animals. These data suggest that although CX3CR1 and CCR2 can both influence vascular inflammation and remodeling, their roles are non-redundant and additive.

\section{Discussion}

Both CX3CR1 and CCR2 are important in the development of coronary artery disease [15]. These receptors may play a role in the migration of monocytes and dendritic cells to the atherosclerotic plaque as well as in the proliferation of vascular smooth muscle cells observed during the vascular remodeling stage. In this study, we show that the compound MRL-677 is a potent and effective antagonist for murine CCR2. In a thioglycollate induced assay of monocyte migration in mice, MRL-677 nearly completely inhibits $\mathrm{F} 4 / 80^{+}$monocyte migration at a dose of $30 \mathrm{mg} / \mathrm{kg}$ (given as oral gavage) which gave trough drug levels of $5 \mathrm{nM}$. However, significant inhibition of monocyte recruitment was also observed at doses of 3 and $10 \mathrm{mg} / \mathrm{kg}$ during which drug levels fell below the $\mathrm{IC}_{50}$ of the compound. Administration of the drug at approximately $15 \mathrm{mg} / \mathrm{kg} /$ day in feed resulted in increased plasma drug levels at trough (PM) with drug levels reaching average levels over $400 \mathrm{nM}$. This is likely due to the fact that the drug is ingested over a prolonged period of time which blunts the peak-to-trough relative to a single oral gavage.

We have also shown that blocking CCR2 with this low molecular weight antagonist ameliorates the inflammatory response to vascular injury. This finding is consistent with previous results using a CCR2 antibody in a rhesus model of vascular injury[16]. Therefore targeting of CCR2 may be a good therapy for reduction of restenosis after angioplasty. However, simultaneous blockade of the CCR2 and CX3CR1 signaling pathways has an even greater effect than blockade of either receptor alone. We have previously published that CX3CR1 deficient mice exhibited a $58 \%$ decrease in intimal hyperplasia compared to wildtype animals $(\mathrm{p}=.0017)[8]$. Among CCR2 antagonist treated animals, the CX3CR1 KO mouse exhibited a significantly lesser degree of intimal hyperplasia on drug compared to the wildtype animals given the drug. This result suggests a complementary and perhaps synergistic effect on the development of the vascular inflammatory response of these two chemokine pathways. Our findings support reports published recently using atherogenic ApoE -/- mice that were 


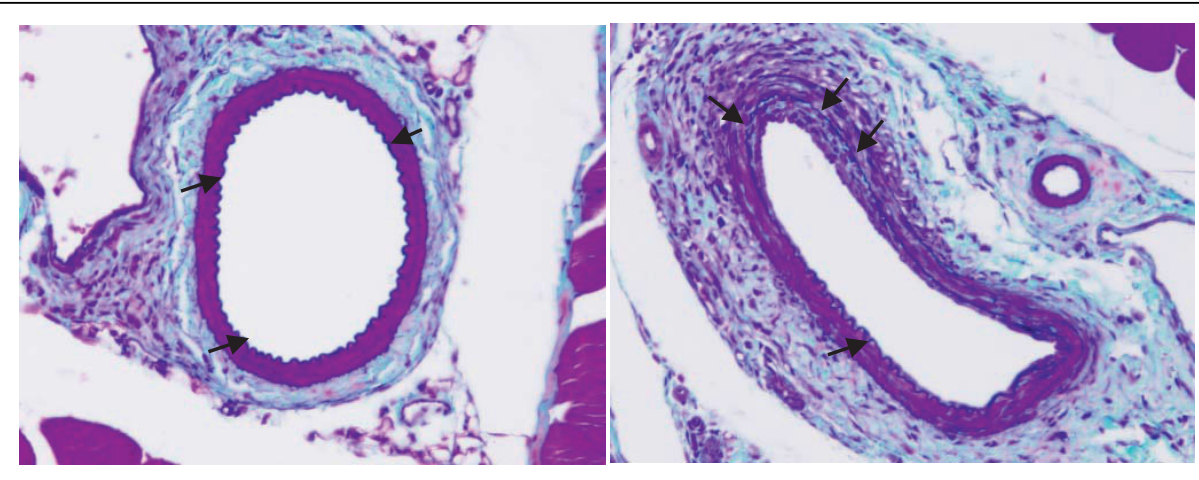

a) Wildtype (WT) uninjured

b) WT

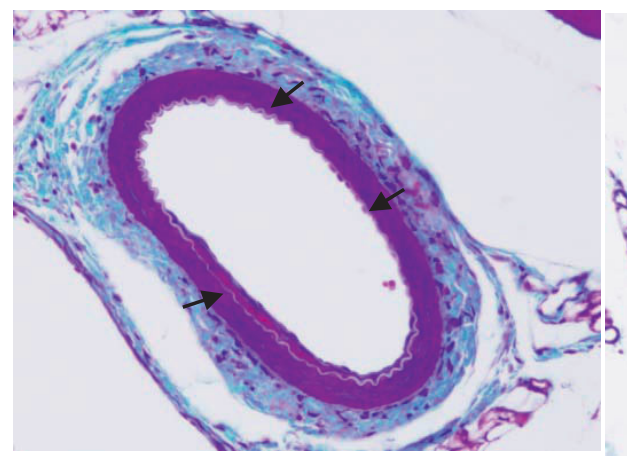

c) WT + MRL-677

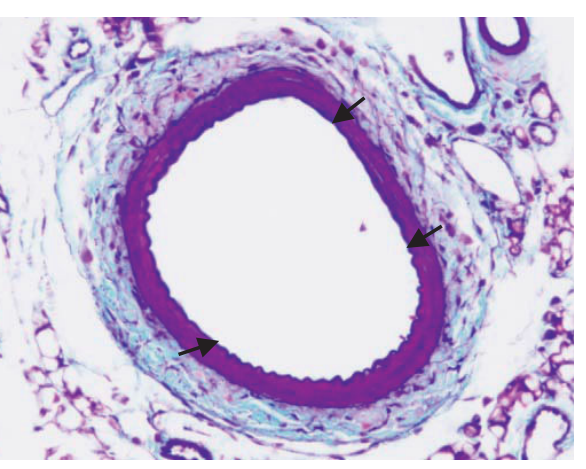

d) CX3CR1 KO + MRL-677

Figure 2 CME stained cross section of mouse femoral artery (a) with no injury and (b)14 days after endoluminal injury in wildtype mouse, (c) wildtype mouse fed CCR2 antagonist, and (d) CX3CR1 KO mouse fed CCR2 antagonist. IEL is marked by arrows. Note the lack of a visible intima with the IEL defining the vessel lumen in the uninjured artery (a). The neointima overlies the IEL in the injured animals (b-d).

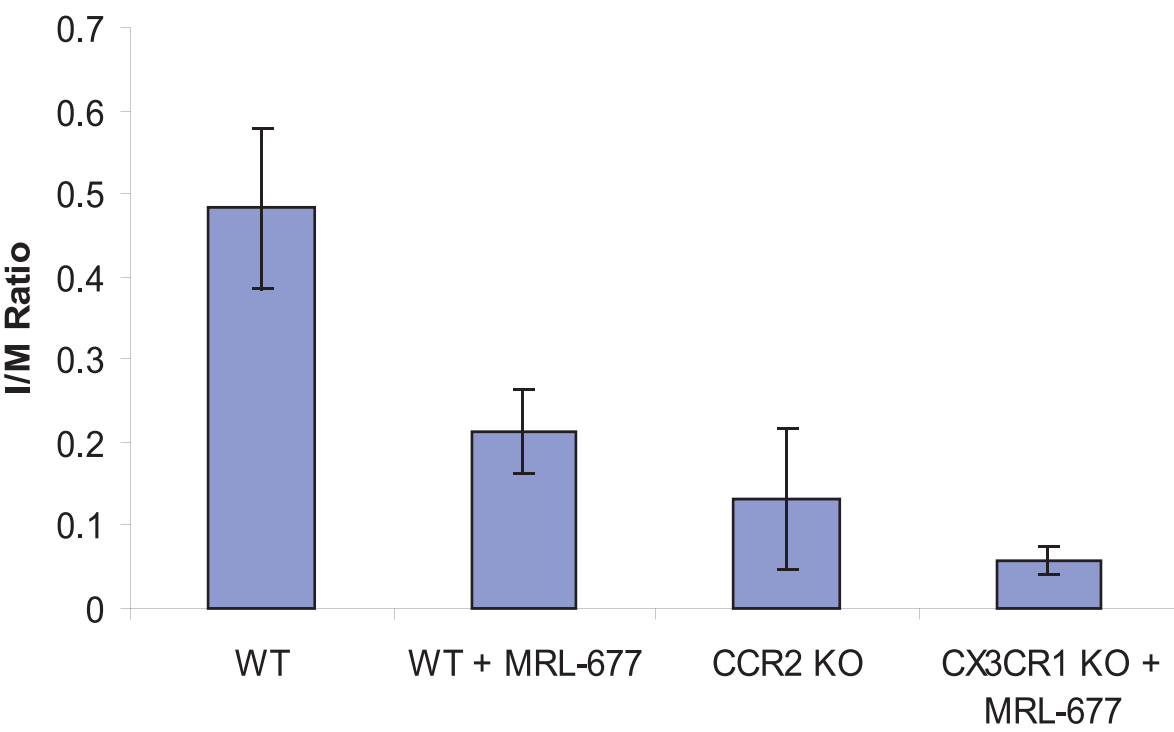

Figure 3 Shown are the average intimal/media ratios for each experimental arm . Graph depicts the mean \pm standard error in each group. Statistical significance was achieved for differences between WT and WT+MRL-677, as well as between WT+MRL-677 and CX3CR1 KO+MRL-677. 


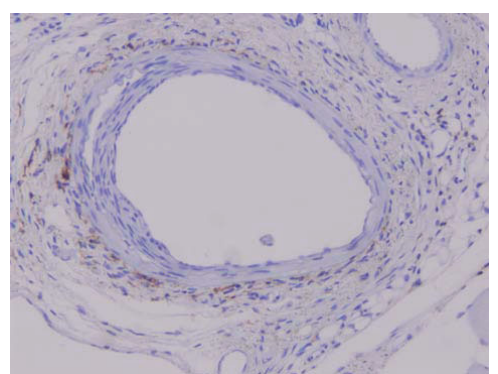

WT

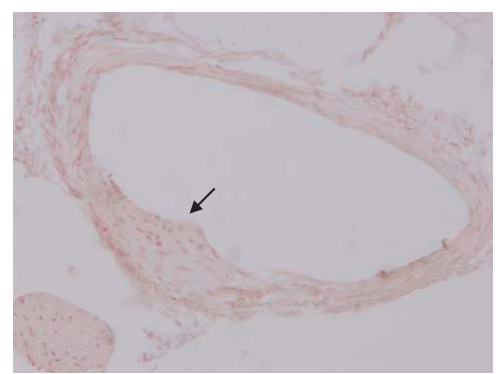

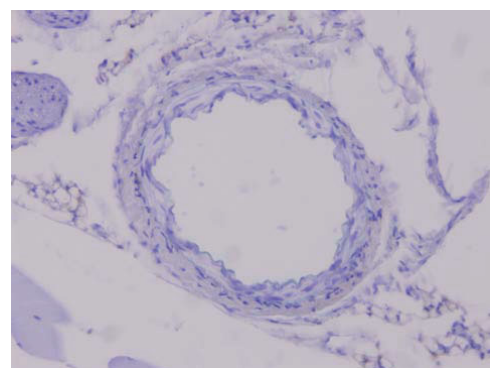

WT+MRL-677

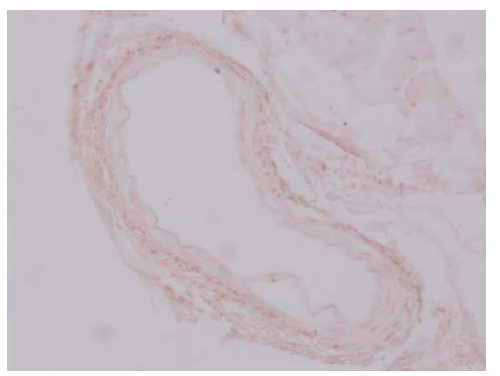

Figure 4 Monocytes within the femoral artery were detected by immunohistochemistry using the F4/80 antibody. A representative section from wildtype animals and those treated with MRL-677 is shown. The top pair of pictures was counterstained in Gills solution.

deficient in both CCR2 and CX3CL1 $[17,18]$. They show that there is reduced macrophage accumulation and atherosclerotic lesion formation in these animals compared to the single knockout mice, suggesting that CX3CR1 and CCR2 can act independently to promote monocyte recruitment to the atherosclerotic lesions. It has been suggested that CCR2 may be important for the migration of monocytes to the atherosclerotic plaque while CX3CR1 may play a larger role in the retention of the monocytes to the lesion[19].

Therefore, our results further imply that CCR2 and CX3CR1 have independent, non-redundant roles in vascular inflammation and the later stages of coronary artery disease. Approaches to target both may have more beneficial effects than targeting each one separately.

\section{Conclusion}

The results of our study indicate that CCR2 and CX3CR1 act by distinct and non-redundant mechanisms to mediate vascular inflammation following arterial injury.

\section{Acknowledgements}

We'd like to thank Kathy Lyons for analysis of MRL-677 drug levels, Hong Jin and Kathleen Sullivan for providing additional information on the affinity of MRL-677 for mouse CCR2 and Mike Forrest for his assistance with the in vivo characterization of MRL-677. This work was partly funded by a grant
(5RO1HL077406) from the National Heart Lung and Blood Institute of the $\mathrm{NIH}$.

\section{Author details}

${ }^{1}$ Department of Medicine, University of North Carolina, Chapel Hill, NC, USA. ${ }^{2}$ Merck \& Co. Rahway, NJ, USA. ${ }^{3}$ Novartis Institutes for Biomedical Research, Basel, Switzerland.

\section{Authors' contributions}

MJ performed the studies and data analysis, PL aided in the studies and analysis (vascular injury model). LP, AC, and RP performed studies and data analysis (monocyte recruitment and whole blood affinity of MRL-677). LY synthesized and provided MRL-677. MS participated in the study design, JD participated in the study design, MR performed the surgeries, DP participated in the study design, and AF performed some experiments and wrote the manuscript. All authors read and approved the final manuscript.

\section{Competing interests}

$M S, L P, A C, J D, R P$ and $L Y$ declare that they are current or former employees of Merck and Company. DP declares that while his involvement in the study was during his employment at the University of North Carolina, he is currently an employee of the Novartis Institutes for Biomedical Research.

Received: 5 October 2009 Accepted: 13 September 2010

Published: 13 September 2010

\section{References}

1. Ross R: Atherosclerosis-an inflammatory disease. N Engl J Med 1999, 340:115-126.

2. Charo IF, Taubman MB: Chemokines in the pathogenesis of vascular disease. Circ Res 2004, 95:858-866.

3. Apostolakis S, Baritaki S, Kochiadakis GE, Igoumenidis NE, Panutsopulos D, Spandidos DA: Effects of polymorphisms in chemokine ligands and receptors on susceptibility to coronary artery disease. Thromb Res 2007 119:63-71.

4. Imai T, Hieshima K, Haskell C, Baba M, Nagira M, Nishimura M, Kakizaki M, Takagi S, Nomiyama H, Schall TJ, Yoshie O: Identification and molecular 
characterization of fractalkine receptor CX3CR1, which mediates both leukocyte migration and adhesion. Cell 1997, 91:521-530.

5. Lucas AD, Bursill C, Guzik TJ, Sadowski J, Channon KM, Greaves DR: Smooth muscle cells in human atherosclerotic plaques express the fractalkine receptor $\mathrm{CX} 3 \mathrm{CR} 1$ and undergo chemotaxis to the $\mathrm{CX} 3 \mathrm{C}$ chemokine fractalkine (CX3CL1). Circulation 2003, 108:2498-2504.

6. Wong BW, Wong D, McManus BM: Characterization of fractalkine (CX3CL1) and CX3CR1 in human coronary arteries with native atherosclerosis, diabetes mellitus, and transplant vascular disease. Cardiovasc Pathol 2002, 11:332-338.

7. Fong AM, Robinson LA, Steeber DA, Tedder TF, Yoshie O, Imai T, Patel DD: Fractalkine and CX3CR1 mediate a novel mechanism of leukocyte capture, firm adhesion, and activation under physiologic flow. J Exp Med 1998, 188:1413-1419.

8. Liu P, Patil S, Rojas M, Fong AM, Smyth SS, Patel DD: CX3CR1 deficiency confers protection from intimal hyperplasia after arterial injury. Arterioscler Thromb Vasc Biol 2006, 26:2056-2062.

9. Liu P, Yu YR, Spencer JA, Johnson AE, Vallanat CT, Fong AM, Patterson C, Patel DD: CX3CR1 deficiency impairs dendritic cell accumulation in arterial intima and reduces atherosclerotic burden. Arterioscler Thromb Vasc Biol 2008, 28:243-250

10. Kuziel WA, Morgan SJ, Dawson TC, Griffin S, Smithies O, Ley K, Maeda N: Severe reduction in leukocyte adhesion and monocyte extravasation in mice deficient in CC chemokine receptor 2. Proc Natl Acad Sci USA 1997, 94:12053-12058

11. Boring L, Gosling J, Cleary M, Charo IF: Decreased lesion formation in CCR2-/- mice reveals a role for chemokines in the initiation of atherosclerosis. Nature 1998, 394:894-897.

12. Roque M, Kim WJ, Gazdoin M, Malik A, Reis ED, Fallon JT, Badimon JJ, Charo IF, Taubman MB: CCR2 deficiency decreases intimal hyperplasia after arterial injury. Arterioscler Thromb Vasc Biol 2002, 22:554-559.

13. Geissmann F, Jung S, Littman DR: Blood monocytes consist of two principal subsets with distinct migratory properties. Immunity 2003, 19:71-82.

14. Li L, Huang L, Sung SS, Vergis AL, Rosin DL, Rose CE Jr, Lobo PI, Okusa MD: The chemokine receptors CCR2 and CX3CR1 mediate monocyte/ macrophage trafficking in kidney ischemia-reperfusion injury. Kidney Int 2008, 74:1526-1537.

15. Schober A: Chemokines in vascular dysfunction and remodeling. Arterioscler Thromb Vasc Biol 2008, 28:1950-1959.

16. Horvath C, Welt FG, Nedelman M, Rao P, Rogers C: Targeting CCR2 or CD18 inhibits experimental in-stent restenosis in primates: inhibitory potential depends on type of injury and leukocytes targeted. Circ Res 2002, 90:488-494.

17. Combadiere C, Potteaux S, Rodero M, Simon T, Pezard A, Esposito B, Merval R, Proudfoot A, Tedgui A, Mallat Z: Combined inhibition of CCL2, CX3CR1, and CCR5 abrogates Ly6C(hi) and Ly6C(lo) monocytosis and almost abolishes atherosclerosis in hypercholesterolemic mice. Circulation 2008, 117:1649-1657.

18. Saederup N, Chan L, Lira SA, Charo IF: Fractalkine deficiency markedly reduces macrophage accumulation and atherosclerotic lesion formation in CCR2-/- mice: evidence for independent chemokine functions in atherogenesis. Circulation 2008, 117:1642-1648.

19. Barlic J, Zhang Y, Foley JF, Murphy PM: Oxidized lipid-driven chemokine receptor switch, CCR2 to CX3CR1, mediates adhesion of human macrophages to coronary artery smooth muscle cells through a peroxisome proliferator-activated receptor gamma-dependent pathway. Circulation 2006, 114:807-819.

doi:10.1186/1477-9560-8-14

Cite this article as: Jerath et al:: Dual targeting of CCR2 and CX3CR1 in an arterial injury model of vascular inflammation. Thrombosis Journal 2010 8:14.

\section{Submit your next manuscript to BioMed Central and take full advantage of:}

- Convenient online submission

- Thorough peer review

- No space constraints or color figure charges

- Immediate publication on acceptance

- Inclusion in PubMed, CAS, Scopus and Google Scholar

- Research which is freely available for redistribution

Submit your manuscript at www.biomedcentral.com/submit
Biomed Central 